\title{
Proprioception following the Anterior Cruciate Ligament Reconstruction with Tibialis Anterior Tendon Allograft
}

\author{
Enes Büyükafşar, MSc, $\mathrm{PT}^{1}$ Selda Başar, $\mathrm{PT}^{2}$ Ulunay Kanatli, MD ${ }^{3}$ \\ ${ }^{1}$ Department of Physical Therapy and Rehabilitation, Ahi Evran \\ University, Kirşehir, Turkey \\ 2 Faculty of Health Sciences, Department of Physiotherapy and \\ Rehabilitation, Gazi University, Ankara, Turkey \\ Address for correspondence Selda Başar, PT, Faculty of Health \\ Sciences, Department of Physiotherapy and Rehabilitation, Gazi \\ University, Muammer Yaşar Bostancı cad. Emniyet Mah. no:16, \\ Ankara 06500, Turkey (e-mail: seldabsr@yahoo.com).
}

${ }^{3}$ Departments of Orthopedics and Traumatology, Gazi University Tıp Fakültesi, Ankara, Turkey

J Knee Surg 2020;33:722-727.

\begin{abstract}
Keywords

- knee surgery

- arthroscopy

- rehabilitation

- proprioception

After the anterior cruciate ligament ( $A C L$ ) reconstruction, a loss of proprioception is observed and it can continue years after the operation. The aim of this study is to evaluate proprioception in standing position at different knee flexion angles in patients who underwent $\mathrm{ACL}$ reconstruction with tibialis anterior tendon allograft. The study included 34 patients who underwent $A C L$ reconstruction with tibialis anterior tendon allograft and 34 healthy individuals. Proprioception was evaluated in standing position at $15^{\circ}, 30^{\circ}, 60^{\circ}$ flexion angles with the active joint position sense (AJPS) method using digital inclinometer. Proprioception deviation angle was found to be higher in the operated leg at $30^{\circ}$ and $60^{\circ}$ flexion angles in the patient group compared with the other leg $(p<0.05)$, the biggest proprioception difference was between the $15^{\circ}$ and $60^{\circ}$ flexion angles in both the patient and the control group $(p<0.05)$ that the difference between $15^{\circ}$ and $30^{\circ}$ flexion angles is lowest $(p<0.05)$, and that these differences are higher in the operated leg of the patient group compared with the other leg of the patient group and to the dominant leg of the control group $(p<0.05)$. As approximately 4 years after $A C L$ reconstruction with tibialis anterior tendon allograft, loss of proprioception at $60^{\circ}$ knee flexion continued, $A C L$ injury related to loss of proprioception may occur at angles higher than $30^{\circ}$ flexion. Thus, patients may be provided with proprioception-enhancing rehabilitation in the long term, particularly, at flexion angles above medium levels.
\end{abstract}

Proprioception is the position sense of the joint and extremity perceived by the mechanoreceptors in joints and the tissues surrounding them. ${ }^{1}$ In knee joint, particularly anterior cruciate ligament is rich in proprioceptive receptors. ${ }^{2-4}$ It was shown that in case of anterior cruciate ligament $(A C L)$ injury or the removal of the ligament following the surgery, proprioception due to the loss of mechanoreceptor decreases. ${ }^{5,6}$ Although mechanical integrity of the ligament is ensured with the ACL reconstruction, it is not yet determined whether sensory integration is ensured or not. ${ }^{7}$

received

July 17,2018

accepted after revision

February 18, 2019

published online

April 8, 2019
It is often revealed that the ACL is injured in the tibia internal rotation in the knee flexion position, or in the activities or positions, in which the knee is forced into valgus when femur is in external rotation. ${ }^{8}$ Deterioration of dynamic stability is one of the primary reasons behind ACL injury. ${ }^{9}$ One important cause of dynamic stability deficit is that enough proprioceptive input cannot be provided.

One of the methods used to assess proprioception is active joint position sense (AJPS) method. ${ }^{10}$ AJPS method allows for the assessment of the stimuli that stimulate both the joint and muscle receptors and that follow afferent paths during

Copyright @ 2020 by Thieme Medical Publishers, Inc., 333 Seventh Avenue, New York, NY 10001, USA. Tel: +1(212) 760-0888.
DOI https://doi.org/ 10.1055/s-0039-1684010. ISSN 1538-8506. 
function. ${ }^{11}$ Inclinometer records angular motions with respect to gravity. It has been found that inclinometer yields more reliable results compared with the universal goniometer that is frequently used in measurement of AJPS. ${ }^{12,13}$ It offers many advantages, some of which are ease of use, precise measurement, digital gauge, and performing measurements in different positions and during various activities. ${ }^{12,13}$

Our literature review revealed that there are few studies on how proprioception is affected in the long-term following ACL reconstruction with tibialis anterior tendon allograft. We propose that in determining proprioception loss, a proprioception assessment that is formed with joint and muscle receptors in dynamic positions is necessary since this loss shows similarities with the injury mechanism. ${ }^{14}$ Thus, our aim in this study is to compare proprioception in different angular positions and in dynamic conditions 4 years after ACL reconstruction with tibialis anterior tendon allograft.

\section{Participants and Methods}

The study included 34 male patients who were operated by the same surgeon and who had undergone ACL reconstruction using the tibialis anterior tendon allograft with the endobutton and rigid fixation method at Gazi University, Orthopedics and Traumatology Department, between 2007 and 2014. The control group consisted of 34 voluntary healthy males at similar ages who have the necessary physical activity level to do the tests. The tests were conducted on similar body parts of the patient and control group. The study was conducted in the Orthopaedics Rehabilitation Unit of the Gazi University, Faculty of Health Sciences, Department of Physiotherapy and Rehabilitation. Ethical consent for the study was obtained from the Gazi University, Faculty of Medicine Clinical Research Ethical Committee. The study was found ethically acceptable with the decision numbered "25901600-3224." Each participant of the study was informed about the content of the study and the evaluations to be made in a detailed manner prior to the evaluations, and an informed consent form was taken from each participant.

The patients who had revision operation in ACL reconstruction, those with multiple ligament injury or meniscus injury, with hip, knee, and ankle pathologies that could cause pain in the knee, and history of cardiopulmonary disease that could prevent the administration of test was not included in the study.

After the reconstruction, all patients were given home exercise program. They used knee-brace for 3 weeks. They were asked to use knee-brace as locked in extension for the $1 \mathrm{st}$ week, then unlocked for the remaining. The first 2 weeks they were asked to apply cold to the knee area. Postoperative beginning from day 1 , range of motion (ROM) exercises were taught. According to the tolerance of the patient, quadriceps, hamstring, and gluteal sets were asked to start. In the first week, ambulation was allowed by applying $25 \%$ of body weight with double crutches. They were asked to increase the weight by $25 \%$. After the 2 nd week, the closed kinetic chain squat exercises were shown (double leg, later one leg). After the 6th week, cycling and progressive resistance exercises were added to the program according to patient tolerance.

Proprioception was evaluated with the AJPS method using digital inclinometer (Dualer IQ, J Tech Medikal). ${ }^{15}$ Digital inclinometer consists of three velcros, two springs to align the device, the main inclinometer and the auxiliary inclinometer, and a connection wire between the inclinometers ${ }^{16}$ (-Fig. 1).

Standing position was chosen as the dynamic position in the evaluation of knee proprioception. Prior to the application, the inclinometer was placed on a flat surface and calibrated at $0^{\circ}$. In the starting position, double-sided velcro were placed on the leg to be tested at proximal and distal locations of the knee so that inclinometers could be fastened. The first inclinometer was fixed to the velcro which was placed on the lateral centerline that runs over the femur lateral epicondyle to trochanter major and lateral epicondyle at the proximal location. The bottom line of the auxiliary inclinometer was fixed to the velcro which was placed on the lateral centerline that runs just below the fibula head to lateral malleolus and fibula head at the distal location. A connection was established between the inclinometers via the Ethernet cable. ${ }^{15-17}$ The participants were positioned at an upright position and hands on hips, with the knee to be tested at extension and the other knee at $15^{\circ}$ to $20^{\circ}$ flexion. ${ }^{12}$
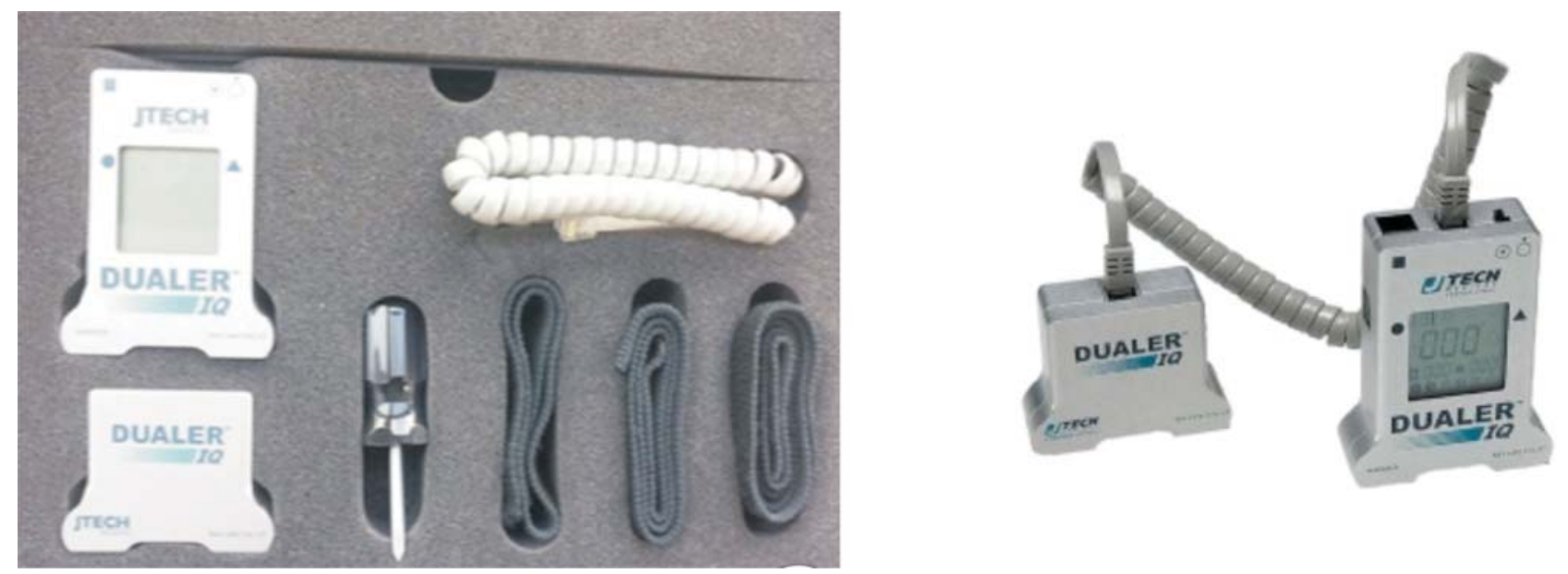

Fig. 1 Digital inclinometer. 

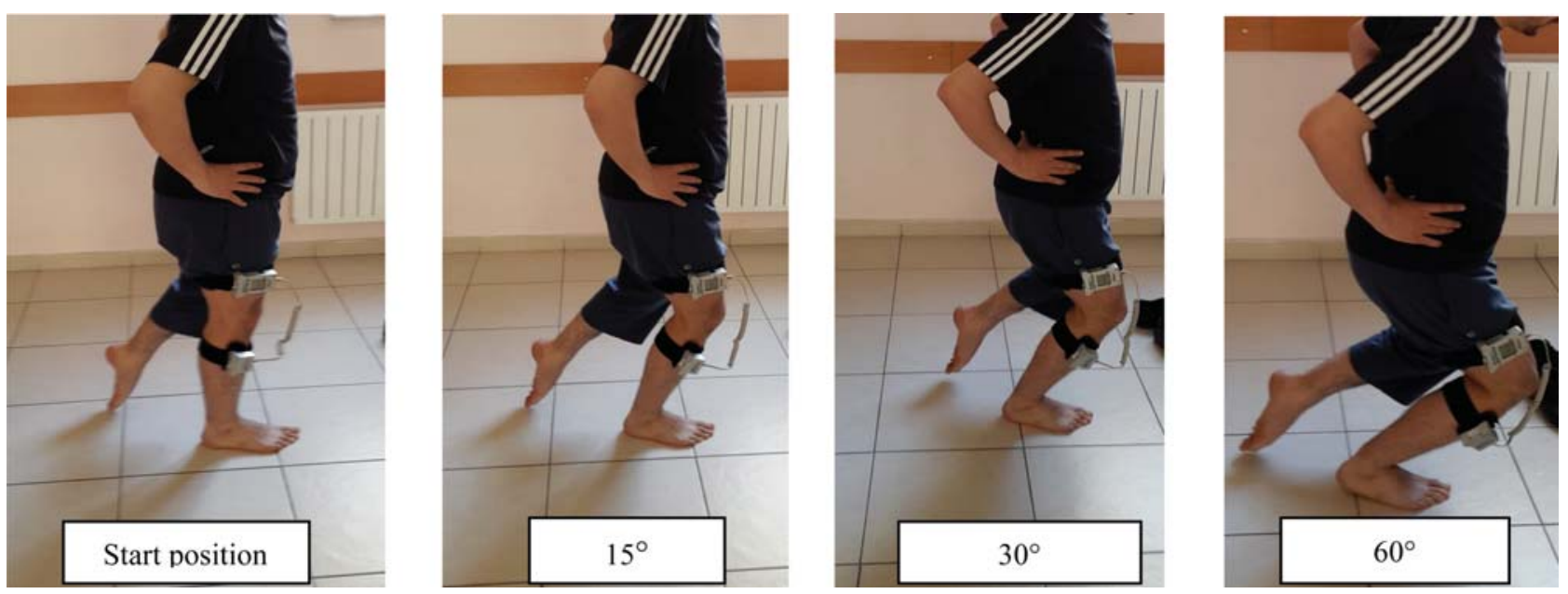

Fig. 2 Proprioception assessment at $15^{\circ}, 30^{\circ}$, and $60^{\circ}$ knee joint flexion

The participants were taught about the target angles determined as $15^{\circ}, 30{ }^{\circ}$ and $60^{\circ}$ by stopping at knee joint flexion for 10 seconds (-Fig. 2). The participants were asked to determine the angle in the next movement. Deviation of the knee joint from the flexion angles of $15^{\circ}, 30^{\circ}$ and $60^{\circ}$ were recorded. The test was started randomly with one of these angles. Triplicate trials were performed at each angle. ${ }^{17,18}$ During the evaluations, the participants rested for a minute after each measurement and different joint angles were followed without a certain order so that tiredness could be prevented and so that the participants do not keep the angles in their memories. Three repetitions were made for each knee at all angles and the mean was calculated. ${ }^{17,18}$

\section{Statistical Analysis}

"Statistical Package for Social Sciences" (SPSS) Version 20.0 (SPSS Inc., Chicago, IL) was used for the statistical analyses. The normal distribution of the data was examined with the "Shapiro-Wilk Test". The variables that were determined with measurements and that show normal distribution were analyzed through "Student's $t$-test." Statistical information was given in the form of mean and standard deviation $(\mathrm{X} \pm \mathrm{SD})$. The variables that were determined through measurements and that do not show normal distribution were indicated as median (25/75 interquartile range [IQR]) with "Mann-Whitney $U$ test." The level of statistical significance was found to be $p<0.05$.

\section{Results}

Age, height, weight, and body mass index (BMI) of the patient group and the control group were similar $(p>0.05$; -Table 1). As seen in - Table 1, the dominant leg and the operated leg of the patient group, and the dominant leg of the control group were the same.

When the proprioception results were compared in the patient group, it was found that the proprioception deviation angle was not different in the operated and nonoperated leg at $15^{\circ}$ flexion, yet it was found to be higher in the operated leg at $30^{\circ}$ and $60^{\circ}$ of flexion compared with the other leg ( $p<0.05$; - Table 2).

When the proprioception results of the dominant and nondominant leg in control group are compared, it was found that proprioception deviation angle was relatively higher in nondominant leg than the other leg at $30^{\circ}$ and $60^{\circ}$ flexion angles ( $p<0.05 ;-$ Table 3 ).

While the proprioception deviation angle was similar in the patient and control group at $15^{\circ}$ and $30^{\circ}$ flexion in

Table 1 Demographic characteristics of the patient group and control group

\begin{tabular}{|c|c|c|c|c|}
\hline & Patient group & Control group & & \\
\hline & $(n=16)$ & $(n=16)$ & & \\
\hline Demographic characteristics & $\mathrm{X} \pm \mathrm{SD}$ & $X \pm S D$ & $t$ & $p$-Value \\
\hline Age $(y)$ & $33 \pm 7.78$ & $32.44 \pm 4.44$ & 0.25 & 0.80 \\
\hline Height (cm) & $176.25 \pm 7.07$ & $174.48 \pm 6.63$ & 0.75 & 0.46 \\
\hline Body weight $(\mathrm{kg})$ & $84.07 \pm 11.26$ & $78.48 \pm 7.67$ & 1.65 & 0.11 \\
\hline Body mass index $\left(\mathrm{kg} / \mathrm{m}^{2}\right)$ & $27.06 \pm 3.26$ & $25.76 \pm 1.97$ & 1.36 & 0.18 \\
\hline Dominant leg (right $[n] /$ left $[n])$ & $16 /-$ & $16 /-$ & & \\
\hline Operated leg (right [n]/left [n]) & $16 /-$ & - & & \\
\hline Time elapsed after operation (y) & $4.35 \pm 2.23$ & & & \\
\hline
\end{tabular}

Abbreviations: $t$, Student's $t$ test; $X \pm S D$, mean \pm standard deviation. 
Table 2 Bilateral proprioception results of the patient group

\begin{tabular}{|l|l|l|l|l|l|}
\hline & \multicolumn{2}{|l|}{ Operated leg } & Other leg & \\
\hline Test angles & $\mathrm{X} \pm \mathrm{SD}$ & Median (IQR) & $\mathrm{X} \pm \mathrm{SD}$ & Median (IQR) & $p$-Value \\
\hline $15^{\circ}$ flexion & $1.89 \pm 0.22$ & $1.85(1.70-2.30)$ & $1.83 \pm 0.19$ & $1.70(1.70-2.30)$ & 0.37 \\
\hline $30^{\circ}$ flexion & $3.33 \pm 0.31$ & $3.30(2.70-3.70)$ & $3.10 \pm 0.21$ & $3.00(2.70-3.30)$ & $0.02^{*}$ \\
\hline $60^{\circ}$ flexion & $5.27 \pm 0.31$ & $5.30(4.70-5.70)$ & $5.02 \pm 0.23$ & $5.00(4.70-5.30)$ & $0.03^{*}$ \\
\hline
\end{tabular}

Abbreviations: IQR, interquartile range; $\mathrm{X} \pm \mathrm{SD}$, mean \pm standard deviation.

*Statistical significance $p<0.05$.

Table 3 Bilateral proprioception results of the control group

\begin{tabular}{|l|l|l|l|l|l|}
\hline & \multicolumn{2}{|l|}{ Dominant leg } & \multicolumn{2}{l|}{ Nondominant leg } & \\
\hline Test angles & $\mathrm{X} \pm \mathrm{SD}$ & Median (IQR) & $\mathrm{X} \pm \mathrm{SD}$ & Median (IQR) & $p$-Value \\
\hline $15^{\circ}$ flexion & $1.78 \pm 0.27$ & $1.85(1.30-2.00)$ & $1.82 \pm 0.29$ & $1.70(1.30-2.30)$ & 0.83 \\
\hline $30^{\circ}$ flexion & $3.08 \pm 0.49$ & $3.30(2.30-3.70)$ & $3.44 \pm 0.27$ & $3.30(3.00-3.70)$ & $0.03^{*}$ \\
\hline $60^{\circ}$ flexion & $4.88 \pm 0.28$ & $4.85(4.30-5.30)$ & $5.08 \pm 0.21$ & $5.00(4.70-5.30)$ & $0.04^{*}$ \\
\hline
\end{tabular}

Abbreviations: IQR, interquartile range; $X \pm S D$, mean \pm standard deviation.

*Statistical significance $p<0.05$.

intergroup comparisons $(p>0.05)$, it was higher in the patient group at $60^{\circ}$ flexion compared with the control group $(p<0.05$; - Table 4).

When the proprioception results at $15^{\circ}, 30^{\circ}$, and $60^{\circ}$ flexion angles in the patient and control groups were compared, a statistically significant difference was found at $15^{\circ}$ to $30^{\circ}, 15^{\circ}$ to $60^{\circ}$, and $30^{\circ}$ to $60^{\circ}$ flexion angles. While the biggest difference was between the $15^{\circ}$ and $60^{\circ}$ flexion angles in both groups, the smallest difference was between $15^{\circ}$ and $30^{\circ}$ flexion angles. These differences were found to be higher in the operated leg of the patient group than the other leg of the patient group and the dominant leg of the control group ( $\mathbf{- T a b l e ~} \mathbf{5}$ ).

\section{Discussion}

In this study, we found that proprioception is similar at $15^{\circ}$ flexion in both legs of the patient and the control group. However, we also found a loss of proprioception in the operated leg at $30^{\circ}$ and $60^{\circ}$ flexion angles. On the other hand, while the proprioception at $15^{\circ}$ and $30^{\circ}$ flexion angles was found to be similar in the patient and the control group, it was also revealed that there was a loss of proprioception in the operated leg at $60^{\circ}$ flexion compared with the control group. Another finding is that proprioception differed between the operated leg and the control group at $15^{\circ}$, $30^{\circ}$, and $60^{\circ}$ flexion angles each.

Proprioception at knee joint is often measured with the "passive and AJPS" method. ${ }^{19-22}$ AJPS stimulates both the joint and the muscle receptors and helps measure the afferent paths in a more functional manner. ${ }^{11}$ However, these two methods are conducted without applying weight on the knee joint. Neither of these tests can differentiate between the proprioceptive sense that comes from the mechanoreceptors on the and the proprioceptive data coming from the surrounding soft tissues and the joint capsule. ${ }^{23}$ To ensure the dynamic stabilization of the knee after the ACL reconstruction, it is important to evaluate the input from joint and muscle receptors in functional positions similar to injury mechanism. ${ }^{10}$ When viewed from this aspect, we thought that it would be more accurate to measure knee proprioception with the AJPS method in addition to the dynamic conditions. Also, instability and decreasing proprioception that occur after the ligament trauma contribute to the formation of functional instability. Thus, we chose to measure knee proprioception in an upright position as the dynamic position (at $15^{\circ}, 30^{\circ}$ and $60^{\circ}$ knee flexion) since the ACL except for direct trauma is similar to the proprioception

Table 4 Comparison of proprioception in the patient and control group

\begin{tabular}{|l|l|l|l|l|l|}
\hline & \multicolumn{2}{|l|}{ Patient group } & \multicolumn{2}{l|}{ Control group } & \\
\hline Test angles & $\mathrm{X} \pm \mathrm{SD}$ & Median (IQR) & $\mathrm{X} \pm$ SD & Median (IQR) & $p$-Value \\
\hline $15^{\circ}$ flexion & $1.89 \pm 0.22$ & $1.85(1.70-2.30)$ & $1.78 \pm 0.27$ & $1.85(1.30-2.00)$ & 0.47 \\
\hline $30^{\circ}$ flexion & $3.33 \pm 0.31$ & $3.30(2.70-3.70)$ & $3.08 \pm 0.49$ & $3.30(2.30-3.70)$ & 0.15 \\
\hline $60^{\circ}$ flexion & $5.27 \pm 0.31$ & $5.30(4.70-5.70)$ & $4.88 \pm 0.28$ & $4.85(4.30-5.30)$ & $0.03^{*}$ \\
\hline
\end{tabular}

Abbreviations: IQR, interquartile range; $\mathrm{X} \pm \mathrm{SD}$, mean \pm standard deviation.

*Statistical significance $p<0.05$. 
Table 5 Comparison of proprioception at different angles in the patient and control group

\begin{tabular}{|c|c|c|c|c|c|c|c|c|c|c|}
\hline & \multicolumn{10}{|c|}{ Test angles compared } \\
\hline & & $\begin{array}{l}15^{\circ}-30^{\circ} \\
\text { flexion }\end{array}$ & Difference & p-Value & $\begin{array}{l}15^{\circ}-60^{\circ} \\
\text { flexion }\end{array}$ & Difference & $p$-Value & $\begin{array}{l}30^{\circ}-60^{\circ} \\
\text { flexion }\end{array}$ & Difference & $p$-Value \\
\hline \multirow[t]{2}{*}{$\begin{array}{l}\text { Patient } \\
\text { group }\end{array}$} & $\begin{array}{l}\text { Operated } \\
\text { knee }\end{array}$ & $1.89-3.33$ & 1.44 & $<0.001$ & $1.89-5.27$ & 3.38 & $<0.001$ & $3.33-5.27$ & 1.94 & $<0.001$ \\
\hline & $\begin{array}{l}\text { Other } \\
\text { knee }\end{array}$ & $1.83-3.10$ & 1.27 & $<0.001$ & $1.83-5.02$ & 3.19 & $<0.001$ & $3.10-5.02$ & 1.92 & $<0.001$ \\
\hline $\begin{array}{l}\text { Control } \\
\text { group }\end{array}$ & $\begin{array}{l}\text { Dominant } \\
\text { leg }\end{array}$ & $1.78-3.08$ & 1.30 & $<0.001$ & $1.78-4.88$ & 3.10 & $<0.001$ & $3.08-4.88$ & 1.80 & $<0.001$ \\
\hline
\end{tabular}

mechanism that occurs during the injury mechanism. This proposition is supported by the literature as well. ${ }^{10}$

Our literature review has shown that a limited number of studies have used tibialis anterior tendon allograft for ACL reconstruction ${ }^{24-26}$ and no studies have yet evaluated the proprioception by measuring the knee joint in more than one angular position. Moreover, the studies in which other grafts are used did not compare proprioception as in our study. When viewed from this perspective, our study seems to be the first study. On the other hand, there are studies in the literature that were performed with different grafts and that compared proprioception at $15^{\circ}$ and $60^{\circ}$ flexion following the $\mathrm{ACL}$ reconstruction with the healthy control group. ${ }^{19-22,27-29}$

Risberg et al found the knee proprioception similar at $15^{\circ}$ knee flexion angle in the patient and the control group approximately 2 years after the anterior cruciate ligament reconstruction with patellar tendon autograft. ${ }^{27}$ Another study used AJPS evaluated proprioception on 15 patient and 15 healthy elite sportsmen with the isokinetic dynamometer 19 months after the ACL reconstruction with hamstring tendon autograft. The same study revealed that knee proprioception at $30^{\circ}$ knee flexion angle was not different in the patient group compared with the healthy group. ${ }^{20}$ Silva et al compared proprioception in the healthy and the patient group with AJPS between $40^{\circ}$ and $60^{\circ}$ flexion angles and the isokinetic dynamometer after the rehabilitation program that lasted for 5 months following the ACL reconstruction. They found that the proprioception error angle of the patient group was lower compared with that of the healthy group. ${ }^{19}$ On the other hand, Angoules et al reported that joint position sense (at $15^{\circ}, 45^{\circ}$, and $75^{\circ}$ ) and time threshold to detection of passive motion returned to normal after 6 months in patients who underwent autograft (hamstring or bone patellar tendon bone). ${ }^{28}$ The same researchers also noted that there was no difference between the two groups used different autograft. Similarly, Ozenci et al found that there was no difference in AJPS compared with the intact leg 25 months after the ACL reconstruction (bone-patellar tendon-bone allograft). ${ }^{29}$ When these studies are examined, it is seen that while the results of $15^{\circ}$ and $60^{\circ}$ knee flexion angle are different, the knee proprioception at $30^{\circ}$ knee flexion angle is similar to the one in our study, in spite of the use of different grafts and methodologies. ${ }^{19-21,27-29}$
In our study, we found that the error angles in the patient group were higher compared with the control group only in the proprioception evaluation at $60^{\circ}$ flexion angle. This may have several reasons. The first reason is loss of mechanoreceptor in the ACL; the second reason is joint movements that exceed medium flexion angles like the $60^{\circ}$ flexion angle of the knee are used less in the standing position and accordingly, proprioception is weaker in $60^{\circ}$ compared with $15^{\circ}$ and $30^{\circ}$ (a similar result was obtained in the healthy group); the third reason could be the fact that following the ACL reconstruction, patients avoid movements that involve such positions because they fear being injured again. Our findings seem to support this assumption in that according to our results, proprioception at $15^{\circ}, 30^{\circ}$, and $60^{\circ}$ flexion angles are different and as the angle increases, proprioception difference also increases.

\section{Limitation}

One limitation of this study is that we did not know the proprioception values of the patient group prior to the ACL reconstruction. Thus, we could not compare the proprioception values of the patients pertaining to approximately 4 years after the ACL reconstruction with values pertaining to the prereconstruction.

\section{Conclusions}

Our study revealed that there was a loss of proprioception at $30^{\circ}$ and $60^{\circ}$ flexion, approximately 4 years after the anterior cruciate ligament reconstruction with tibialis anterior tendon allograft. It was also found that the biggest proprioception difference was between the $15^{\circ}$ and $60^{\circ}$ flexion angles in both the patient and the control group that the difference between $15^{\circ}$ and $30^{\circ}$ flexion angles is lowest, and that these differences are higher in the operated leg of the patient group compared with the other leg of the patient group and to the dominant leg of the control group. As approximately 4 years after the ACL reconstruction with tibialis anterior tendon allograft, loss of proprioception at $60^{\circ}$ knee flexion continued, ACL injury related to loss of proprioception may occur at angles higher than $30^{\circ}$ flexion.

Conflict of Interest

None declared. 


\section{References}

1 Hughes T, Rochester P. The effects of proprioceptive exercise and taping on proprioception in subjects with functional ankle instability: a review of the literature. Phys Ther Sport 2008;9(03):136-147

2 Zimny ML, Schutte M, Dabezies E. Mechanoreceptors in the human anterior cruciate ligament. Anat Rec 1986;214(02):204-209

3 Johansson H, Sjölander P, Sojka P. Receptors in the knee joint ligaments and their role in the biomechanics of the joint. Crit Rev Biomed Eng 1991;18(05):341-368

4 Zimny ML. Mechanoreceptors in articular tissues. Am J Anat 1988; 182(01):16-32

5 Katayama M, Higuchi H, Kimura M, et al. Proprioception and performance after anterior cruciate ligament rupture. Int Orthop 2004;28(05):278-281

6 Reider B, Arcand MA, Diehl LH, et al. Proprioception of the knee before and after anterior cruciate ligament reconstruction. Arthroscopy 2003;19(01):2-12

7 Young SW, Valladares RD, Loi F, Dragoo JL. Mechanoreceptor reinnervation of autografts versus allografts after anterior cruciate ligament reconstruction. OrthopJ Sports Med 2016;4(10):2325967 116668782

8 Hull ML. Analysis of skiing accidents involving combined injuries to the medial collateral and anterior cruciate ligaments. Am J Sports Med 1997;25(01):35-40

9 Alonso AC, Greve JM, Camanho GL. Evaluating the center of gravity of dislocations in soccer players with and without reconstruction of the anterior cruciate ligament using a balance platform. Clinics (São Paulo) 2009;64(03):163-170

10 Prentice WE. Rehabilitation Techniques in Sport Medicine. 2nd ed. St. Louis: Mosby; 1994:118-125

11 Lephart SM, Pincivero DM, Giraldo JL, Fu FH. The role of proprioception in the management and rehabilitation of athletic injuries. Am J Sports Med 1997;25(01):130-137

12 Adams MA, Dolan P, Marx C, Hutton WC. An electronic inclinometer technique for measuring lumbar curvature. Clin Biomech (Bristol, Avon) 1986;1(03):130-134

13 Mellin G. Measurement of thoracolumbar posture and mobility with a Myrin inclinometer. Spine 1986;11(07):759-762

14 Yosmaoğlu HB, Baltacı G, Kaya D, Ozer H, Atay A. Comparison of functional outcomes of two anterior cruciate ligament reconstruction methods with hamstring tendon graft. Acta Orthop Traumatol Turc 2011;45(04):240-247

15 Romero-Franco N, Montaño-Munuera JA, Jiménez-Reyes P. Validity and reliability of a digital inclinometer to assess knee joint-position sense in a closed kinetic chain. J Sport Rehabil 2017;26(01):1-16

16 JTECH Medical System, Dualer IQ. The Smarter Inclinometer. Operation Manuel Book,. Salt Lake City, Utah: JTECH Medical
17 Chouteau J, Testa R, Viste A, Moyen B. Knee rotational laxity and proprioceptive function 2 years after partial ACL reconstruction. Knee Surg Sports Traumatol Arthrosc 2012;20(04):762-766

18 Cho YR, Hong BY, Lim SH, et al. Effects of joint effusion on proprioception in patients with knee osteoarthritis: a singleblind, randomized controlled clinical trial. Osteoarthritis Cartilage $2011 ; 19(01): 22-28$

19 Silva F, Ribeiro F, Oliveira J. Effect of an accelerated ACL rehabilitation protocol on knee proprioception and muscle strength after anterior cruciate ligament reconstruction. Arch Exerc Health Dis 2012;3:139-144

20 Ghasemi GA, Zolaktaf V, Minasian KI. Evaluation of joint position sense after acl reconstruction with hamstring tendon autograft. Am J Sports Sci Med 2013;1(03):52-55

21 Mir SM, Hadian MR, Talebian S, Nasseri N. Functional assessment of knee joint position sense following anterior cruciate ligament reconstruction. Br J Sports Med 2008;42(04):300-303

22 Karasel S, Akpinar B, Gülbahar S, et al. Clinical and functional outcomes and proprioception after a modified accelerated rehabilitation program following anterior cruciate ligament reconstruction with patellar tendon autograft. Acta Orthop Traumatol Turc 2010;44(03):220-228

23 Hogervorst T, Brand RA. Mechanoreceptors in joint function. J Bone Joint Surg Am 1998;80(09):1365-1378

24 Lawhorn KW, Howell SM, Traina SM, Gottlieb JE, Meade TD, Freedberg HI. The effect of graft tissue on anterior cruciate ligament outcomes: a multicenter, prospective, randomized controlled trial comparing autograft hamstrings with fresh-frozen anterior tibialis allograft. Arthroscopy 2012;28(08):1079-1086

25 Li J, Wang J, Li Y, Shao D, You X, Shen Y. A prospective randomized study of anterior cruciate ligament reconstruction with autograft, $\gamma$-irradiated allograft, and hybrid graft. Arthroscopy 2015;31(07): 1296-1302

26 Sun R, Chen BC, Wang F, Wang XF, Chen JQ. Prospective randomized comparison of knee stability and joint degeneration for double- and single-bundle ACL reconstruction. Knee Surg Sports Traumatol Arthrosc 2015;23(04):1171-1178

27 Risberg MA, Beynnon BD, Peura GD, Uh BS. Proprioception after anterior cruciate ligament reconstruction with and without bracing. Knee Surg Sports Traumatol Arthrosc 1999;7(05):303-309

28 Angoules AG, Mavrogenis AF, Dimitriou R, et al. Knee proprioception following ACL reconstruction; a prospective trial comparing hamstrings with bone-patellar tendon-bone autograft. Knee 2011;18(02):76-82

29 Ozenci AM, Inanmaz E, Ozcanli H, et al. Proprioceptive comparison of allograft and autograft anterior cruciate ligament reconstructions. Knee Surg Sports Traumatol Arthrosc 2007;15(12):1432-1437 